\title{
Doctors' knowledge of the law on withholding and withdrawing life- sustaining medical treatment
}

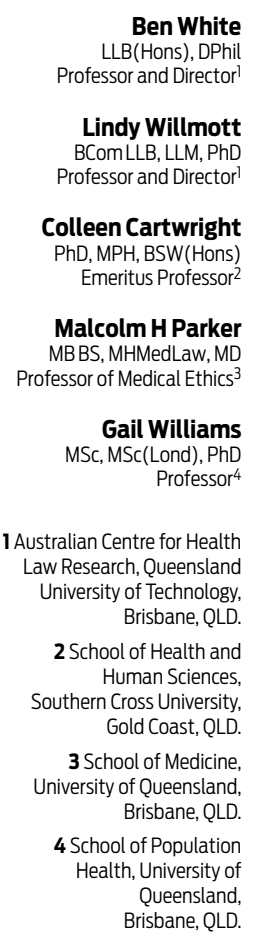

bp.white@qut.edu.au

MJA 2014; 201: 1-4 doi: 10.5694/mjal3.00217

Online first 11/08/14
D ecisions to withhold or withdraw life-sustaining treatment are part of mainstream medical practice..$^{1}$ Almost 40000 adult deaths occur each year across Australia following a medical decision to withhold or withdraw life-sustaining treatment. ${ }^{2}$

Doctors play a critical clinical role in the provision of medical treatment at the end of life. What is less recognised is that doctors also play a significant legal role in that process. ${ }^{2-4}$ For example, a doctor must assess whether a patient has the capacity to make a treatment decision, determine who the authorised decisionmaker is if the patient does not have that capacity, and know whether a person's previously expressed wishes comprise a valid advance directive that must be followed.

Further, the law in this field is complex and differs between states and territories. For example, in some situations a doctor may be obliged to follow an advance directive in one state but will be in breach of the law if he or she does so in the same situation in another.

Doctors currently receive some training about the law in this and other areas in medical school, during specialist training, and/or as part of continuing medical education. ${ }^{3}$ However, it is unclear whether this training equips doctors sufficiently with adequate practical knowledge. One aim of this research was to establish the level of doctors' legal knowledge about withholding or withdrawing life-sustaining treatment from adults who lack decision-making capacity.

\section{Methods}

This study explored doctors' knowledge of the law relevant to end-of-life care in New South Wales, Victoria and

\section{Abstract}

Objectives: To examine doctors' level of knowledge of the law on withholding and withdrawing life-sustaining treatment from adults who lack decisionmaking capacity, and factors associated with a higher level of knowledge.

Design, setting and participants: Postal survey of all specialists in emergency medicine, geriatric medicine, intensive care, medical oncology, palliative medicine, renal medicine and respiratory medicine on the AMPCo Direct database in New South Wales, Victoria and Queensland. Survey initially posted to participants on 18 July 2012 and closed on 31 January 2013.

Main outcome measures: Medical specialists' levels of knowledge about the law, based on their responses to two survey questions.

Results: Overall response rate was 32\%. For the seven statements contained in the two questions about the law, the mean knowledge score was 3.26 out of 7 . State and specialty were the strongest predictors of legal knowledge.

Conclusions: Among doctors who practise in the end-of-life field, there are some significant knowledge gaps about the law on withholding and withdrawing lifesustaining treatment from adults who lack decision-making capacity. Significant consequences for both patients and doctors can flow from a failure to comply with the law. Steps should be taken to improve doctors' legal knowledge in this area and to harmonise the law across Australia.

Queensland. These states have both similarities and differences between legal regimes, which allowed us to explore whether the different regimes affected levels of knowledge.

Data were collected through a survey instrument, developed over 18 months, informed by a detailed review of the law in each state, focus groups, pretesting, and piloting of the instrument with specialists. The accuracy of the legal questions and responses were confirmed by independent legal experts in each state.

The sample cohort comprised all specialists in emergency medicine, geriatric medicine, intensive care, medical oncology, palliative medicine, renal medicine and respiratory medicine who were on the AMPCo Direct (a subsidiary of the Australian Medical Association) database in the three states at the time the instrument was distributed $(n=2858)$. These specialties were chosen as these specialists are likely to be involved in making decisions about whether to withhold or withdraw life-sustaining treatment.
This was determined by a review of relevant literature, interviews and an analysis of pilot results. Although general practitioners are commonly involved in end-of-life decision making, they were excluded from our study, which focused on the acute care setting.

AMPCo Direct administered the survey mailout, which began on 18 July 2012. Recruitment strategies included having the survey instrument professionally designed, providing incentives (continuing professional development [CPD] points, educational material and a chance to win one of six prestige bottles of wine), engaging with all the colleges and specialist societies of the target specialties (except the emergency medicine society given the overlap with the college) and publishing editorials in relevant professional journals to request participation in the study. 5,6 Two follow-up requests were sent to non-responders and the survey was closed on 31 January 2013.

The project was approved by the human research ethics committees at the 
1 Mean correct responses to seven statements relating to knowledge of the law regarding end-of-life care, and number of respondents scoring $\geqslant 4$, by doctor characteristics

\begin{tabular}{|c|c|c|c|c|}
\hline Characteristic & $\begin{array}{l}\text { No. of } \\
\text { respondents }\end{array}$ & $\begin{array}{l}\text { Mean correct } \\
\text { score (SD) }\end{array}$ & $\begin{array}{l}\text { Adjusted mean } \\
\text { score* }\end{array}$ & $\begin{array}{l}\text { No. of respondents } \\
\text { scoring } \geqslant 4(\%)\end{array}$ \\
\hline Total & 867 & $3.26(1.32)$ & & $365(42.1 \%)$ \\
\hline \multicolumn{5}{|l|}{ State } \\
\hline New South Wales & 335 & $3.65(1.24)$ & & $185(55.2 \%)$ \\
\hline Victoria & 314 & $3.17(1.38)$ & & $124(39.5 \%)$ \\
\hline Queensland & 218 & $2.79(1.18)$ & & $56(25.7 \%)$ \\
\hline \multicolumn{5}{|l|}{ Specialty ${ }^{\dagger}$} \\
\hline Geriatric medicine & 107 & $3.89(1.28)$ & 3.77 & $61(57.0 \%)$ \\
\hline Palliative medicine & 52 & $3.71(1.49)$ & 3.69 & 27 (51.9\%) \\
\hline Intensive care & 125 & $3.48(1.35)$ & 3.44 & $63(50.4 \%)$ \\
\hline Renal medicine & 80 & $3.37(1.13)$ & 3.28 & $37(46.3 \%)$ \\
\hline Emergency medicine & 270 & $3.09(1.27)$ & 3.04 & $103(38.1 \%)$ \\
\hline Medical oncology & 80 & $3.07(1.23)$ & 3.00 & $29(36.3 \%)$ \\
\hline Respiratory medicine & 98 & $2.72(1.34)$ & 2.68 & $25(25.5 \%)$ \\
\hline \multicolumn{5}{|l|}{ Sext } \\
\hline Male & 567 & $3.18(1.30)$ & 3.08 & $232(40.9 \%)$ \\
\hline Female & 298 & $3.43(1.35)$ & 3.26 & $132(44.3 \%)$ \\
\hline \multicolumn{5}{|l|}{ Country of birth ${ }^{\dagger}$} \\
\hline Australia & 517 & $3.35(1.32)$ & 3.41 & $231(44.7 \%)$ \\
\hline Other English-speaking & 151 & $3.23(1.42)$ & 3.23 & $65(43.0 \%)$ \\
\hline Asia & 120 & $3.12(1.18)$ & 3.08 & $45(37.5 \%)$ \\
\hline Europe & 31 & $2.87(1.31)$ & 3.01 & $7(22.6 \%)$ \\
\hline Other & 43 & $3.12(1.35)$ & 3.14 & 15 (34.9\%) \\
\hline
\end{tabular}

Queensland University of Technology, the University of Queensland and Southern Cross University.

\section{Measures}

The survey instrument had six sections: perspectives about the law; education and training; knowledge of the law; practice of and compliance with the law; experience in making endof-life decisions; and demographics. The knowledge section contained two questions. The first comprised six items: three concerning the validity of an advance directive, two concerning consent from and the authority of substitute decisionmakers, and one dealing with both issues. All questions were to be answered True, False or Don't Know in relation to the relevant state law. The second question asked which of four plausible decisionmakers had legal authority to make medical decisions for a patient without capacity. Participants could score correct responses on a scale of 0 to 7 (Don't Know was scored as an incorrect response).
Doctors were asked how much knowledge of the relevant law they felt that they currently had: very little; some; moderate; or considerable.

To determine any correlation between decision making and knowledge, doctors were asked how many decisions to withhold or withdraw life-sustaining treatment they were directly involved in as a member of the treating team in the previous 12-month period, including situations where such decisions were considered but treatment was ultimately provided or continued.

To determine any correlation between the extent of CPD training received in this area and knowledge, doctors were asked whether they had received such training and, if so, when.

\section{Statistical analysis}

Questionnaires were coded and double-entered into an Access database and transferred to SPSS Statistics 20 (IBM) and SAS 9.3 (SAS Institute Inc) for analyses.
Preliminary analyses examined descriptive statistics and bivariate associations by $\chi^{2}$ tests. Mean scores were calculated to assess differences in knowledge among subgroups and linear trends associated with ordinal variables. Formal comparison of mean scores was performed using a general linear model, assuming a normal distribution for scores. Variables examined as predictors of knowledge were state, age, sex, main specialty, religion, years of practice, country of birth, country of degree, self-perceived knowledge of the law, number of decisions made in relation to withholding and withdrawing life-sustaining treatment, and CPD training. Mean scores for subgroups were compared with the sample average using the Nelson-Hsu method within the SAS Statistics GLM procedure, which also adjusts for multiplicity of comparisons. Linear trends associated with ordinal variables, such as self-perceived knowledge, were assessed by modelling these as continuous. Likelihood ratio tests (LRTs) were used to assess each variable overall. Adjusted means were obtained from a linear model that included selected covariates, and similarly compared.

\section{Results}

The final overall response rate was 32\% (867/2702): 29\% (335/1147) from NSW, 33\% (314/957) from Victoria and 36\% (218/598) from Queensland. Response rates by specialty by state ranged from $75 \%$ for palliative medicine specialists in Victoria to 22\% for oncologists in NSW.

The mean correct response for the knowledge of law questions overall was 3.26 (out of a possible score of 7), with a standard deviation of 1.32 .

State and specialty were the strongest predictors of knowledge (Box 1), with LRTs giving $P_{L R T}<0.001$ for both variables. NSW showed the highest scores and Queensland the lowest. All pairwise differences were statistically significant at $P<0.001$. After adjustment for state, specialists in geriatric medicine $(P<0.001)$ and in palliative medicine $(P=0.033)$ had significantly higher scores than average, and specialists in emergency medicine $(P=0.035)$ and respiratory medicine $(P<0.001)$ had significantly lower scores than average. Medical 
oncologists had a lower mean score than average but this was not significant $(P=0.53)$, because of the small number of medical oncologists.

Sex and country of birth were weaker predictors of knowledge. Women and Australian-born doctors scored somewhat higher than other groups. The sex effect is reduced when adjusted as described in Box 1, but remains significant $\left(P_{L R T}=0.05\right)$. Country of birth was also a significant predictor after adjustment $\left(P_{L R T}=0.042\right)$. The difference between Australian-born doctors and others was significant after adjustment for state, specialty and $\operatorname{sex}(P=0.017)$.

Years of practice, age, country of degree and religion did not predict knowledge (data not shown).

The results demonstrated a highly significant and linear association between doctors' perception of and actual knowledge of the law in this area (Box 2; $P<0.001)$. This effect remained after adjusting for state, specialty, sex and country of birth $(P<0.001)$.

The results also demonstrated a highly significant and linear association between the number of decisions doctors made and their knowledge of the law (Box 2; $P<0.001$ ), an effect which remained after adjustment for state, specialty, sex and country of birth $(P=0.008)$.

Doctors who had received $\mathrm{CPD}$ training had greater knowledge than those who had not, and the association between knowledge and recency of training was significant and linear (Box 2; $P=0.007$ for linear trend in mean scores, after adjusting for state, specialty, sex and country of birth).

\section{Discussion}

Our results demonstrate critical gaps in the legal knowledge of many doctors who practise end-of-life medicine. Before considering the consequences of these gaps, and the implications of these results, we make two general observations.

First, doctors in NSW had the highest level of knowledge, followed by those in Victoria and then Queensland. Research into reasons for the disparity between states is needed and may provide guidance for successful education and training strategies. Is the law easier to understand in some

2 Mean correct responses to seven statements relating to knowledge of the law regarding end-of-life care, and number of respondents scoring $\geqslant 4$, by perception of knowledge, number of decisions made in relation to withholding and withdrawing life-sustaining treatment, and timing of most recent continuing professional development (CPD) training

\begin{tabular}{|c|c|c|c|c|}
\hline & $\begin{array}{l}\text { No. of } \\
\text { respondents }\end{array}$ & $\begin{array}{l}\text { Mean correct } \\
\text { score (SD) }\end{array}$ & $\begin{array}{l}\text { Adjusted mean } \\
\text { score* }\end{array}$ & $\begin{array}{l}\text { No. of respondents } \\
\text { scoring } \geqslant 4(\%)\end{array}$ \\
\hline \multicolumn{5}{|c|}{ Perceived knowledge of law ${ }^{\dagger}$} \\
\hline Very little & 136 & $2.83(1.25)$ & 2.84 & $39(28.7 \%)$ \\
\hline Some & 330 & $3.15(1.21)$ & 3.06 & 129 (39.1\%) \\
\hline Moderate & 258 & $3.42(1.39)$ & 3.31 & $117(45.3 \%)$ \\
\hline Considerable & 42 & $4.14(1.34)$ & 4.03 & $30(71.4 \%)$ \\
\hline \multicolumn{5}{|l|}{ No. of decisions ${ }^{\dagger}$} \\
\hline None & 60 & $3.00(1.30)$ & 2.86 & $21(35.0 \%)$ \\
\hline $1-10$ & 345 & $3.08(1.25)$ & 3.10 & $122(35.4 \%)$ \\
\hline $11-30$ & 249 & $3.31(1.34)$ & 3.26 & $112(45.0 \%)$ \\
\hline $31-50$ & 105 & $3.60(1.39)$ & 3.44 & $54(51.4 \%)$ \\
\hline $51-100$ & 68 & $3.44(1.30)$ & 3.21 & $33(48.5 \%)$ \\
\hline$>100$ & 34 & $3.88(1.32)$ & 3.51 & $21(61.8 \%)$ \\
\hline \multicolumn{5}{|c|}{ Most recent CPD training ${ }^{\dagger}$} \\
\hline None & 343 & $3.07(1.37)$ & 3.07 & $126(36.7 \%)$ \\
\hline$\geqslant 5$ years ago & 107 & $3.30(1.26)$ & 3.20 & $46(43.0 \%)$ \\
\hline $3-4$ years ago & 132 & $3.33(1.32)$ & 3.14 & $59(44.7 \%)$ \\
\hline $1-2$ years ago & 143 & $3.36(1.25)$ & 3.29 & $63(44.1 \%)$ \\
\hline Within past year & 126 & $3.60(1.30)$ & 3.43 & $67(53.2 \%)$ \\
\hline
\end{tabular}

*Adjusted for state, specialty, sex and country of birth. $\uparrow 101,6$ and 16 respondents did not answer the questions on knowledge, number of decisions and CPD training, respectively.

jurisdictions? Does the law reflect good medical practice to a greater extent in some jurisdictions? Are doctors in some jurisdictions better trained in the law? Further, respondents in some specialties were more knowledgeable than those in other specialties.

Second, the results indicate that doctors have an accurate perception of their level of knowledge. This may be useful if doctors are persuaded that it is important to be familiar with the law in the course of their clinical practice. As they have insight into their level of knowledge, they will know whether further efforts are needed to augment that knowledge.

There are limitations to research of this kind. Doctors with an interest in law may be more likely to respond, so our sample may be more legally knowledgeable than the wider medical population. Also, not all aspects of legal knowledge about withholding or withdrawing treatment can be tested. However, two important aspects of the law were explored: validity and effect of advance directives and the authority of substitute decisionmakers. The results show that many doctors do not possess sufficient legal knowledge to determine whether an advance directive presented to them is valid. Further, even if they are confident that it is valid, many doctors do not know whether they are legally obliged to follow a directive that refuses treatment in a situation when providing treatment is clinically indicated. The results also indicate doctors' lack of knowledge in determining the legally authorised decisionmaker for medical treatment where there are various people who have an interest in the wellbeing of a patient.

Significant consequences for patients can flow from a failure to know and comply with the law. Life-sustaining treatment may be unlawfully withheld or withdrawn; for example, where the purported decisionmaker lacks legal authority. For patients, the outcome of such decisions is that, at least as a matter of law, their lives are being ended wrongly. Conversely, life-sustaining treatment may be unlawfully provided; for example, despite a lawful refusal of treatment through an advance directive or by a substitute decisionmaker. This may infringe a patient's legal rights, including their right to bodily integrity, ${ }^{7}$ and cause patients to survive 
with poor quality of life, which they had sought to avoid. ${ }^{8}$

For medical professionals, criminal responsibility could arise for murder or manslaughter (where treatment is withheld or withdrawn unlawfully) ${ }^{9}$ or for assault (where treatment is provided without appropriate consent or authorisation). ${ }^{10} \mathrm{~A}$ lack of legal knowledge will not excuse a medical professional from liability. ${ }^{11}$ Claims of civil liability may also flow from such actions, along with disciplinary or coronial proceedings. ${ }^{12}$

In addition, conflict may arise where medical professionals and patients' family or friends have little or no legal knowledge, or different understandings of what the law requires, leading to adverse consequences for everyone involved. ${ }^{13}$

Our findings strongly suggest that doctors in a specialty involving endof-life decision making should improve their knowledge of the law, in the interests of their patients and for their own protection. To achieve this goal, three things must occur: legal reform; improved training and resources; and a shift in doctors' attitudes to knowing the law.

We have argued elsewhere that there are problems with the law in NSW, ${ }^{2}$ Victoria ${ }^{3}$ and Queensland, ${ }^{4}$ and have identified aspects that could be simplified. Some level of legal complexity in this area is unavoidable, but where it is unnecessary, the law should be reformed. There is also an urgent need for a national approach to the law in this area. ${ }^{14}$ For medical professionals, a single Australian legislative framework, or a harmonised national approach, is likely to be easier to know and understand.

Training in medical law remains uneven and unsystematic at all stages of medical education. ${ }^{15}$ This is reflected in the general knowledge deficits and variations by specialty demonstrated by our research, only partly offset by knowledge gained by practical involvement (the number of decisions).
Nevertheless, the correlation between knowledge level and recent CPD training is promising. Even if a harmonised national approach to the law in this area were to be achieved, the need for a substantial increase in educational effort would remain to ensure that all doctors involved in end-of-life care know and understand the applicable law. We advocate a broad approach to improving doctors' knowledge of the law across the three main stages of medical education and note those with responsibility for change:

- undergraduate training in basic ethical principles and the related law at the end of life, within a wider framework of dedicated coursework in ethics, law and professional practice (universities and medical schools, Australian Medical Council);

- continuing training for interns and junior doctors in the hospital setting, in relevant rotations, as components of educational packages under accreditation requirements (hospital executives, directors of clinical training, medical education officers, specialist consultant leaders, intern training accreditation bodies, Medical Board of Australia); and

- specialist college-sponsored, nonelective training programs in all specialties concerned with end-oflife decision making (specialist colleges, Australian Medical Council). However, providing training opportunities and resources - even in the format and at the times most desired by doctors - is not enough. Attitudes must also shift; doctors who are under ever-increasing time pressures must be satisfied that knowing the law is valuable. Learning about and understanding the law that applies at the end of life will require significant intellectual engagement and commitment of time. The challenge is convincing doctors that it is worth the effort. A good start is to ensure that doctors recognise that lack of legal knowledge places their patients' interests and rights at risk — and them at legal risk.

Received 13 Dec 2013, accepted 15 Jul 2014.

Acknowledgements: We thank the Australian Research Council (project no. LP0990329), NSW Guardianship Tribunal, NSW Public Guardian, Office of the Public Advocate (Vic), Victorian Civil and Administrative Tribunal, Queensland Civil and Administrative Tribunal, Office of the Public Guardian (Qld) and Office of the Public Advocate (Qld) for funding this research. We also thank Stephanie Jowett for research assistance.

Competing interests: No relevant disclosures.

1 White B, Willmott L, Allen J. Withholding and withdrawing life-sustaining treatment: criminal responsibility for established medical practice? J Law Med 2010; 17: 849-865.

2 White B, Willmott L, Trowse P, et al. The legal role of medical professionals in decisions to withhold or withdraw life-sustaining treatment: Part 1 (New South Wales). J Law Med 2011; 18: 498-522.

3 Willmott L, White B, Parker M, et al. The legal role of medical professionals in decisions to withhold or withdraw life-sustaining treatment: Part 3 (Victoria). J Law Med 2011; 18: 773-797.

4 Willmott L, White B, Parker M, et al. The legal role of medical professionals in decisions to withhold or withdraw life-sustaining treatment: Part 2 (Queensland). J Law Med 2011; 18: 523-544.

5 White B, Willmott L, Parker M, et al. Should law have a role in end-of-life care? Intern Med J 2012; 42: 966-967.

6 White B, Willmott L, Parker M, et al. What do emergency physicians think of the law? Emerg Med Australas 2012; 24: 355-356.

7 Parker M, Stewart C, Willmott L, et al. Two steps forward, one step back: advance care planning, Australian regulatory frameworks and the Australia Medical Association. Intern Med J 2007; 37: 637-643.

8 Gilligan T, Raffin TA. Whose death is it, anyway? Ann Intern Med 1996; 125: 137-141.

9 Willmott L, White B, Then S-N. Withholding and withdrawing life-sustaining medical treatment. In: White B, McDonald F, Willmott L, editors. Health law in Australia. 2nd ed, Sydney: Thomson Reuters, 2014.

10 Hunter and New England Area Health Service $v A$ (2009) 74 NSWLR 88: [40].

11 Bronitt S, McSherry B. Principles of criminal law. 3rd ed. Sydney: Thomson Reuters, 2010.

12 Inquest into the Death of June Woo (Unreported, Queensland Coroner's Court, State Coroner Barnes SM, 1 Jun 2009).

13 CRELS Project Working Group. Conflict resolution in end of life settings (CRELS). Sydney: NSW Department of Health, 2010.

14 House of Representatives Standing Committee on Legal and Constitutional Affairs. Older people and the law. Canberra: Parliament of Australia, 2007.

15 Preston-Shoot M, McKimm J. Towards effective outcomes in teaching, learning and assessment of law in medical education. Med Educ 2011; 45: 339-346. 